\title{
A Novel Three Drug Rigemen (Moxifloxacin -Omeprazole - Nitazoxanide) in Comparison to Traditional Triple Therapy for Treatment and Eradication of Naïve and Resistant H. Pylori Infection in Dyspeptic Patients
}

\author{
Ahmed Abd El Aleem Ahmed, Mohammed Zakaria Abu Amer, Mahmoud Mostafa Abd El Hamid* \\ Department of Tropical Medicine, Faculty of Medicine, El-Azhar University \\ * Corresponding author: Mahmoud Mostafa Abd El Hamid, Mobile: (+20)01000962976, E-mail: dr7oodasamar@gmail.com
}

\begin{abstract}
Background: Helicobacter pylori is one of the most common, medically prominent infection worldwide and one of the major causative factor of peptic ulcer disease. So, eradication of $\mathrm{H}$. pylori is effective in healing ulcers, reducing the ulcer recurrence and eliminating the need for maintenance therapy.

Objective: The aim of the work was to compare between the efficacy of traditional triple therapy and Moxifloxacin-based triple therapy in treatment of $\mathrm{H}$. pylori infection and to evaluate the efficacy of moxifloxacin-based regimens as a rescue regimen for $\mathrm{H}$. pylori eradication in resistant patients.

Patients and methods: This study was carried out on $\mathbf{1 0 0}$ Helicobacter pylori (H. pylori)-infected patients (within the period between septemper, 2018 to May, 2019) who were enrolled from Hepatology, Gastroenterology \& Tropical Medicine Department, Al Azhar University Hospitals (El-Hussein and BAB El-Shaarea).

Results: Helicobacter pylori eradication results in group III as evaluated by monoclonal H. Pylori stool Ag, 6 weeks post therapeutic regimens reported that eradication rate was $76.9 \%$ (20 patients). Regarding post treatment clinical data in group III, $42.3 \%$ of patients remained having symptoms and $57.7 \%$ had acheived symptomatic improvement. Also, the best results were recorded for H.pylori eradication (90\%) in group II who received moxifloxacin based triple therapy compared to group I (with eradication rate 62.9\%) who received traditional triple therapy regimen. Thus the better results (76.9\%) were achieved in group III (resistant patients from group I).
\end{abstract}

Conclusion: The present results could state that moxifloxacin can overcome traditional triple therapy resistance.

Keywords: H.Pylori, Moxifloxacin, Omeprazole, Nitazoxanide, Traditional triple therapy.

\section{INTRODUCTION}

Helicobacter pylori (H. pylori) is a small gramnegative spirochete that inhabits the mucous layer overlying the gastric epithelial cells in humans. It is the most common prevalent chronic human bacterial infection estimated in $50 \%$ of the global population (1) and the most common cause of gastritis worldwide ${ }^{(2)}$.

Gastric mucus colonization with $\mathrm{H}$. pylori induces chronic gastric inflammation in all infected individuals, but only induces clinical diseases in 10$20 \%$ of infected individuals. These include peptic ulcers, acute and atrophic gastritis, intestinal metaplasia, gastric adeno-carcinoma and gastric B-cell lymphoma ${ }^{(3)}$. The preferred treatment for $\mathrm{H}$. pylori infection involves; proton pump inhibitor (PPI)-based triple or quadruple regimens ${ }^{(4)}$. PPI, amoxicillin \& clarithromycin is one of a global standard care for confirmed H. pylori infection (2). Metronidazole (MNZ) is used instead of amoxicillin or clarithromycin in cases of allergy or resistance ${ }^{(5)}$.

Current guidelines from the American College of Gastroenterology and the European Helicobacter Study Group recommend either a clarithromycin-based triple therapy (a proton pump inhibitor (PPI) plus amoxicillin and clarithromycin) or a bis-muth quadriple therapy (a PPI plus bismuth, metronidazole, and tetracycline) as a standard of care in the treatment of confirmed HP infections ${ }^{(2)}$. However, a study by Rokkas et al. ${ }^{(2)}$ based on the Maastricht III guidelines, indicated that treatment with a PPI, amoxicillin, and clarithromycin regimen as first-line therapy failed in $\sim 30 \%$ of patients on an intention-to-treat (ITT) basis and treatment with PPI, bismuth, metronidazole, and tetracycline as second-line therapy failed in another $30 \%$, leaving $\sim 10 \%$ of the total patient population in need of an alternative regimen.

Moxifloxacin, a bactericidal fluoroquinolone antibiotic, has activity against HP due primarily to the drug's activity on bacterial DNA gyrase. Moxifloxacin has been advocated for use in second- and third-line "rescue" regimens. Unfortunately, fluoroquinolone resistance, especially in patients who had routinely received a fluoroquinolone for other indications, is of particular concern ${ }^{(6)}$. A lower dose of moxifloxacin was used to aid in the tolerability of this three-drug regimen, how-ever, as moxifloxacin is a concentrationdependent agent, higher doses may increase eradication rates. Although the optimal dose of moxifloxacin is yet to be determined, our study demonstrated efficacy using the lower dose of $400 \mathrm{mg}$ once daily. Considering the regimen, it was well tolerated overall. An increase in moxifloxacin dosage may be warranted ${ }^{(7)}$.

Nitazoxanide is a thiazolide antibiotic indicated for use in adults and children for the treatment of Cryptosporidium and Giardia infections. Unlike metronidazole, nitazoxanide has been shown to be non-mutagenic for HP and to possess antivacuolating toxin activity. In vitro studies indicated that nitazoxanide is a potent agent against HP and other anaerobes and having activity against 
metronidazole-resistant strains ${ }^{(8)}$. In addition to the in vitro data, others reported clinical success using nitazoxanide in a two-drug regimen combined with a PPI or sucralfate and a three-drug regimen with a PPI and amoxicillin ${ }^{(9)}$.

Nitazoxanide (NTZ), the first anti-parasitic agent, reported to be effective against both protozoa and helminthes, particularly intestinal parasitic infestation. NTZ also showed significant immune-modulation properties inhibiting lipo-polysaccharide (IPS) -induced pro-inflammatory cytokine production in macrophages (10). NTZ was used as a mono-therapy, as it was a new drug that was unlikely to be affected by the antibiotic resistance of strains in patients who had previous failed therapies (11). Moreover; Levofloxcicin, PPI, NTZ \& doxycycline (LOND) regimen had very good results (90\% cure rate) in $\mathrm{H}$. pylori infection that was reported by Basu et al. ${ }^{(12)}$.

\section{AIM OF THE WORK}

The aim of the work was to compare between the efficacy of traditional triple therapy and moxifloxacinbased triple therapy in treatment of H.pylori infection and to evaluate the efficacy of moxifloxacin-based regimens as a rescue regimen for $\mathrm{H}$. pylori eradication in resistant patients.

\section{PATIENTS AND METHODS}

1. Type of the study: A case control study.

2. Place: Al Azhar University Hospitals (ElHussein and BAB El-Shaarea).

3. Study population: This study was carried out on 100 Helicobacter pylori (H. pylori) infected patients within the period between septemper, 2018 and May, 2019) who were enrolled from Hepatology, Gastroenterology \& Tropical Medicine Department.

The enrolled patients were divided into 3 groups:

Group I: 70 naïve (not previously took or received a particular treatment for $H$. pylori) patients with positive $\mathrm{H}$. Pylori Ag had traditional triple therapy (amoxicillin 1gm twice daily, clarithromycin $500 \mathrm{mg}$ twice daily and a PPI $40 \mathrm{mg}$ once daily) fo 14 days.

Group II: 30 patients with positive H. pylori stool Ag who received moxifloxacin-based triple therapy composed of moxifloxacin (400mg once daily) Nitazoxanide (500 mg twice daily) \& a PPI (40 mg once daily) for $\mathbf{1 0}$ days.

Group III: 26 patients with positive H. pylori Ag after treatment (resistant for triple therapy from group 1). They received been taken 10 days of Moxifloxacin-based triple therapy (Moxifloxacin $400 \mathrm{mg}$ once daily, Nitazoxanide $500 \mathrm{mg}$ twice daily \& PPI $40 \mathrm{mg}$ once daily) for 10 days. The patients were distributed randomly among the studied groups.

Ethical approval:

- The study was approved by Ethical Committee of Faculty of Medicine, AlAzhar University.
- Written informed consents were taken from all participants in the study and also they were informed by any probable side effects that may happen to them.

4. Inclusion criteria:

- Patients with dyspeptic symptoms AND having H. Pylori stool Ag +ve.

- $\quad$ Age $>18$ yrs old.

5. Exclusion Criteria:

- Active GIT bleeding.

- Recent use of antibiotics (within 6 weeks).

- Pregnancy and lactating women.

- Previous treatment for HP.

- Allergy to any medication included in the study.

- GIT malignancy.

6. Initial evaluation:

All the studied subjects were subjected to:

A-Complete history taking and clinical assessment:

- Stressing on symptoms of upper gastrointestinal tract (GIT) disorders e.g. nausea, vomiting, regurgitation, epigastric pain, heart burn, eructation, fullness, dyspepsia and hematemesis or melena.

- Full general and abdominal examinations.

B- Laboratory evaluation:

- Complete blood count (CBC).

- Liver function tests: AST, ALT, S.Albumin.

- Renal function tests: S.Creatinine, S.Urea

C-Stool analysis

D- Stool H. pylori antigen:

The test was done at start of study and 6 weeks after completion of treatment therapy for both groups (I \& II).

Stool samples: were taken using clean cans. The collected samples were sent immediately to the laboratory to be investigated for:

Helicobacter pylori stool antigen (HpSA) using immune-card test (Epitope Diagnostics Inc.,) was conducted at the diagnosis \& 6 weeks after the full course of treatment regimens ${ }^{(13)}$.

Sample store: The test can be performed on either fresh or frozen stool samples. If the test cannot be performed within one day, the specimen was stored at $-20^{\circ} \mathrm{C}$ or colder.

Test procedure: Add a stool sample of 100 $\mathrm{mg}$ to $1 \mathrm{ml}$ of the sample dilution buffer and homogenize thoroughly on a Vortex-mixer. Immundiagnostic recommends for sample preparation.

\section{Data management and statistic analysis}

Data were collected, coded, revised and entered to the Statistical Package for Social Science (SPSS) version 20. The data were presented as number and percentages for the qualitative data and mean, standard deviations and ranges for the quantitative data with parametric distribution as well as median with inter quartile range (IQR) for the quantitative data with non parametric distribution. Chi-square test was used in the comparison between two groups with qualitative 
data and Fisher exact test was used instead of the Chisquare test when the expected count in any cell found to be less than 5. Independent t-test was used in the comparison between two groups with quantitative data and parametric distribution and Mann-Whitney test was used in the comparison between two groups with quantitative data and non parametric distribution.
The confidence interval was set to $95 \%$ and the margin of error accepted was set to $5 \%$. So, the pvalue was considered significant as the following:

- $\quad \mathrm{P}>0.05$ : Non significant (NS)

- $\quad \mathrm{P}<0.05$ : Significant $(\mathrm{S})$

- $\mathrm{P}<0.01$ : Highly significant (HS)

\section{RESULTS}

Table (1): Comparison between group I \& group II as regards Age \& Sex

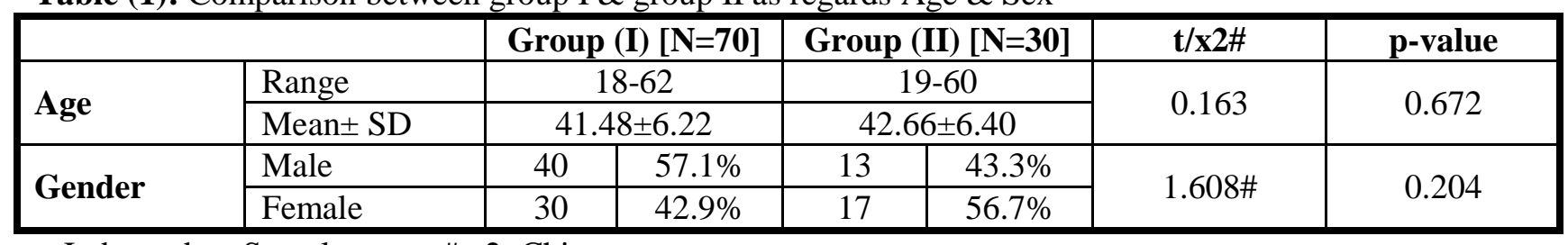

t- Independent Sample t-test; \# x2: Chi-square test

This table showed no statistically significant difference between groups according to age \& sex.

Table (2): Comparison between group I \& group II as regards main GIT injurious agents in the studied groups.

\begin{tabular}{|c|c|c|c|c|c|c|}
\hline \multirow{2}{*}{$\begin{array}{c}\text { Injurious agents for patients' } \\
\text { GIT disorders }\end{array}$} & \multicolumn{2}{|c|}{$\begin{array}{c}\text { Group (I) } \\
{[\mathrm{N}=70]}\end{array}$} & \multicolumn{2}{|c|}{$\begin{array}{c}\text { Group (II) } \\
{[\mathbf{N}=30]}\end{array}$} & \multirow[t]{2}{*}{$\mathbf{x} 2$} & \multirow[t]{2}{*}{ p-value } \\
\hline & No & $\%$ & No & $\%$ & & \\
\hline NSAIDs & 8 & $11.4 \%$ & 5 & $16.7 \%$ & \multirow{5}{*}{2.455} & \multirow{5}{*}{0.653} \\
\hline Smoking & 11 & $15.7 \%$ & 6 & $20.0 \%$ & & \\
\hline outdoor fast food & 25 & $35.7 \%$ & 10 & $33.3 \%$ & & \\
\hline caffeine & 15 & $21.4 \%$ & 3 & $10.0 \%$ & & \\
\hline more than one factor & 11 & $15.7 \%$ & 6 & $20.0 \%$ & & \\
\hline
\end{tabular}

$\mathrm{x} 2$ : Chi-square test; $\mathrm{p}$-value $>0.05 \mathrm{NS}$

This table showed no statistically significant difference between groups regarding injurious agents for patients' GIT disorders.

Table (3): Comparison between clinical presentation before $\mathrm{ttt}$ and after $\mathrm{ttt}$ in group I.

\begin{tabular}{|c|c|c|c|c|c|c|c|}
\hline \multicolumn{2}{|c|}{} & \multicolumn{2}{c|}{ Before treatment } & \multicolumn{2}{c|}{ After treatment } & \multicolumn{2}{c|}{ Chi square test } \\
\cline { 3 - 8 } & No & $\%$ & No & $\%$ & $\mathbf{X}^{\mathbf{2}}$ & P value \\
\hline \multirow{2}{*}{ Clinical presentation } & Asymptomatic & 0 & $0.0 \%$ & 16 & $22.9 \%$ & \multirow{2}{*}{18.065} & 0.001 \\
\cline { 2 - 8 } & Symptomatic & 70 & $100.0 \%$ & 54 & $77.1 \%$ & \\
\hline
\end{tabular}

This table showed statistically significant difference between clinical presentation before treatment and after treatment in group $\mathrm{I}$.

Table (4): Comparison between clinical presentation before $\mathrm{ttt}$ and after $\mathrm{ttt}$ in group II.

\begin{tabular}{|c|c|c|c|c|c|c|c|}
\hline & & \multicolumn{2}{|c|}{$\begin{array}{c}\text { Before } \\
\text { treatment }\end{array}$} & \multicolumn{2}{|c|}{$\begin{array}{c}\text { After } \\
\text { treatment }\end{array}$} & \multicolumn{2}{|c|}{$\begin{array}{c}\text { Chi square } \\
\text { test }\end{array}$} \\
\hline & & No & $\%$ & No & $\%$ & $\mathbf{X}^{2}$ & $P$ value \\
\hline \multirow{2}{*}{$\begin{array}{c}\text { Clinical } \\
\text { presentation }\end{array}$} & Asymptomatic & 0 & $0.0 \%$ & 18 & $60 \%$ & \multirow{2}{*}{$\begin{array}{c}25 . \\
71 \\
4\end{array}$} & \multirow[b]{2}{*}{0.001} \\
\hline & $\begin{array}{l}\text { Symptomatic(heart } \\
\text { burn,regurgitation,nusea/vomiting) }\end{array}$ & 30 & $\begin{array}{l}100.0 \\
\%\end{array}$ & 12 & $40 \%$ & & \\
\hline
\end{tabular}

This table showed statistically significant difference between clinical presentation before treatment and after treatment in group II.

Table (5): Comparison between group I \& group II regarding post therapeutic eradication results.

\begin{tabular}{|c|c|c|c|c|c|c|c|}
\hline \multirow{2}{*}{} & \multicolumn{2}{|c|}{$\begin{array}{c}\text { Group I (triple therapy) } \\
\text { No=70 }\end{array}$} & \multicolumn{2}{c|}{$\begin{array}{c}\text { Group II (moxifloxacin-based } \\
\text { therapy) -No=30 }\end{array}$} & \multicolumn{2}{c|}{$\begin{array}{c}\text { Chi square } \\
\text { test }\end{array}$} \\
\cline { 3 - 8 } \multicolumn{2}{|c|}{} & No & \% & No & \% & $\mathbf{X}^{\mathbf{2}}$ & P value \\
\hline \multirow{2}{*}{ H pylori } & Negative & 44 & $62.9 \%$ & 27 & $76.9 \%$ & \multirow{2}{*}{7.514} & \multirow{2}{*}{0.006} \\
\cline { 2 - 8 } & Positive & 26 & $37.1 \%$ & 3 & $23.1 \%$ & \\
\hline
\end{tabular}

This table showed statistically significant difference between groups concerning H pylori eradication. 
Table (6): Comparison between clinical presentation before ttt and after ttt in group III.

\begin{tabular}{|c|c|c|c|c|c|c|c|}
\hline \multicolumn{2}{|c|}{} & \multicolumn{2}{c|}{$\begin{array}{c}\text { Before } \\
\text { treatment }\end{array}$} & \multicolumn{2}{c|}{ After treatment } & \multicolumn{2}{c|}{ Chi square test } \\
\cline { 2 - 8 } \multicolumn{2}{|c|}{} & No & $\mathbf{\%}$ & No & $\%$ & $\mathbf{X}^{\mathbf{2}}$ & P value \\
\hline \multirow{3}{*}{$\begin{array}{c}\text { Clinical } \\
\text { presentation }\end{array}$} & Asymptomatic & 0 & $0.0 \%$ & 15 & $57.7 \%$ & & \\
\cline { 2 - 6 } & $\begin{array}{c}\text { Symptomatic } \\
\text { (heart burn, regurgitation, } \\
\text { nusea/vomiting) }\end{array}$ & 26 & $100.0 \%$ & 11 & $42.3 \%$ & 21.081 & 0.001 \\
\hline
\end{tabular}

This table showed statistically significant difference between clinical presentation before treatment and after treatment in group III

Table (7): Comparison between group II \& group III as regards H. pylori eradication.

\begin{tabular}{|c|c|c|c|c|c|c|c|}
\hline \multirow{2}{*}{} & \multicolumn{2}{|c|}{ Group II } & \multicolumn{2}{c|}{ Group III } & \multicolumn{2}{c|}{ Chi square test } \\
\cline { 3 - 8 } \multicolumn{2}{|c|}{} & No & $\%$ & No & \% & $\mathbf{X}^{\mathbf{2}}$ & P value \\
\hline \multirow{2}{*}{ H pylori } & Negative & 27 & $90.0 \%$ & 20 & $76.9 \%$ & \multirow{2}{*}{1.766} & 0.184 \\
\cline { 2 - 9 } & Positive & 3 & $10.0 \%$ & 6 & $23.1 \%$ & \\
\hline
\end{tabular}

This table showed no statistically significant difference between groups according to $\mathrm{H}$ pylori.

\section{DISCUSSION}

In this study, we tried to compare between the current \& new moxifloxacin- based therapeutic regimens for Helicobacter pylori (H. pylori) infection to overcome the problem of resistance with the current regimens. Moxifloxacin-based regimens were recently studied showing interesting results without the apparent problem of resistance as in metronidazole or clarythromycin with nearby cost.

The recorded high frequency of $\mathrm{H}$. pylori infection in this study, with upper gastrointestinal tract related symptoms and documented gastritis could be due to the fact that El-Hussein and BAB ELShaarea University Hospitals are receiving a wide range of population with a relatively poor socioeconomic status and overcrowded conditions.

One-handred H. pylori patients were included in the research and randomly distributed into two groups according to the received regimens of therapy for H. pylori. Group I (70 patients) who received the traditional treatment regimen of amoxicillin ( $1 \mathrm{gm}$ twice daily), clarithromycin (500 mg twice daily) and PPI (40 mg once daily) for 14 days. A case of clarithromycin allergy appeared within the study as a dermatological rash, stopped treatment and replaced with another case. A case of Amoxicillin associated diarrhea (for 5 days) appeared within the study, stopped treatment and replaced with another case. Group II (30 patients) who received moxifloxacinbased regimen consisted of moxafloxacin $(400 \mathrm{mg}$ once daily), nitazoxanide (500 mg twice daily) and a PPI (omeprazole $40 \mathrm{mg}$ once daily) for 10 days.

Regarding sex and age; 53 males and 47 females were included in the study with males were slightly more than females. Sex distributions among the two studied groups were (40 males and 30 females) in group I and (13 males and 17 females) in group II; with no statistically significant difference between the studied groups.

The mean age of the patients among the studied groups was $41.48 \pm 6.22$ years (ranged between 18 and 62 years) in group I and $42.66 \pm 6.40$ years (ranged between 19 and 60 years) in group II with no statistically significant difference between the studied groups.

On history taking from the studied groups, the reported suspected injurious agents for their GIT disorders were out door fast food, smoking, non steroidal anti-inflammatory drugs (NSAIDS), caffeine and more than one factor of mentioned factors with percentages of $35.7 \%, 15.7 \%, \mathbf{1 1 . 4 \%}$, $\mathbf{2 1 . 4 \%}$ and $\mathbf{1 5 . 7 \%}$ respectively in group I and $\mathbf{3 3 . 3 \%}$, $20 \%, 16.7 \%, 10 \%$ and $20 \%$ respectively) in group II without statistically significant difference between the studied groups. These reported suspected injurious agents for the studied patients' disorders agree with Laine et al. ${ }^{(14)}$ and also agree with Begovic and Selmani ${ }^{(15)}$.

Helicobacter pylori eradication results as evaluated by H.pylori monoclonal stool antigen, 6 weeks post therapeutic regimens reported that eradication rate was $62.9 \%$ (44 patients) in group I and $90 \%$ (27 patients) in group II with statistically significant difference between the studied groups.

Regarding post treatment clinical data; (22.9\%) of patients became asymptomatic and (77.1\%) still symptomatic (heart burn, regurgitation and nusea/vomiting) in group I with statistically significant difference between pretherapeutic and post therapeutic clinical presentation. While, in group 
II (40\%) remained symptomatic and (60\%) improved there symptoms with highly statistically significant difference between pretherapeutic and post therapeutic clinical presentation.

This work studied $\mathrm{H}$. pylori therapeutic regimens based on moxifloxacin in $\mathrm{H}$. pylori in Egyptian patients to explore moxifloxacin efficacy in our community and to evaluate the efficacy of nitazoxanide as a rescue regimen for $\mathrm{H}$. pylori eradication in resistant patients.

So the 26 resistant cases of group I were included in group III and received moxifloxacinbased triple therapy composed of moxifloxacin (400 $\mathrm{mg}$ once daily), nitazoxanide (500 mg twice daily) and PPI (Omeprazole $40 \mathrm{mg}$ once daily).

Helicobacter pylori eradication results in group III as evaluated by monoclonal H. Pylori stool Ag 6 weeks post therapeutic regimens, reported that eradication rate was $76.9 \%$ (20 patients). Regarding post treatment clinical data in group III, $42.3 \%$ of patients remained having symptoms and $57.7 \%$ had acheived symptomatic improvement. So, this work recorded the best results for $\mathrm{H}$. pylori eradication $(90 \%)$ in group II who received moxifloxacin-based triple therapy compared to group I eradication rate $(62.9 \%)$ who received traditional triple therapy regimen and better results $(76.9 \%)$ in group III (resistant patients comoared to group I). Group I who received clarithromycin, PPI and amoxicillin regimen achieved the least eradication rate $(62.9 \%)$ with a lot of residual complaints. These results agree with Yakoob et al. (16) who reported that patients were treated with PPI (40 mg daily), clarythromycin (500 $\mathrm{mg}$ ) and amoxicillin (1 $\mathrm{g}$ twice a day) for 14 days. A 14C Urea breath test was repeated four weeks after completion of treatment to confirm eradication. Triple therapy failure was seen in 30/92 (33\%) patients. The resistance rates were: CLR 33\% (30/92 and AMX 2\% (2/92).

Also agree with Kobtan et al. (17) who reported that a 370 patients infected with $\mathrm{H}$. pylori received the standard triple therapy (PPI twice daily, $500 \mathrm{mg}$ clarithromycin twice daily and either $1 \mathrm{~g}$ amoxicillin or 500mg metronidazole twice daily for 2 weeks). Eradication was successful in only 223 patients $(60.27 \%)$ raising questions if $\mathrm{H}$. pylori is still responding to standard triple therapy.

The present results also agree with Malfertheiner et al. ${ }^{(1)}$ who stated that in areas of low clarithromycin resistance, including the United States, a 14-day course of "triple therapy" with an oral proton pump inhibitor, clarithromycin $500 \mathrm{mg}$ and amoxicillin $1 \mathrm{~g}$ (or, if penicillin allergic, metronidazole $500 \mathrm{mg}$ ). All were given twice daily for 14 days. This regimen is still recommended for first-line therapy. This regimen only achieves rates of eradication in up to $70 \%$ of cases. The present results disagree with the study reported by Higuchi et al. ${ }^{(18)}$ who stated that $\mathrm{H}$. pylori eradication rates were $80 \%$ (116/145 patient) in the group who received the highdose (PPI $40 \mathrm{mg} /$ day + amoxicillin $2 \mathrm{gm} /$ day + clarithromycin $800 \mathrm{mg} /$ day).

Group II who received Moxifloxacin, Nitazoxanide, and PPI regimen achieved the best eradication rate $(90 \%)$ with a minimal residual complaints. These agree with Hwang et al. ${ }^{(19)}$ who reported that the response to moxifloxacin-based sequential triple therapy versus hyprid therapy as a first line treatment for H. Pylori was $91.3 \%$.

Also, these results agree also with Mona et al. ${ }^{(20)}$ who reported that the response to treatment of nitazoxanide was significantly higher than traditional treatment regimen. One hundred and six cases (94.6\%) of 112 patients who completed the study showed complete cure, while only 63 cases $(60.6 \%)$ of 104 patients (received triple therapy) showed the same response.

\section{CONCLUSION}

So the present results could state that moxifloxacin can overcome traditional triple therapy resistance. In addition to its efficacy in treating naiive patients (who didn't take any medical treatment) with $90 \%$ and $76.9 \%$ success rate in resistant patients with shorter therapeutic coarse duration and better patient compliance.

\section{RECOMMENDATIONS}

- Improving the standard of living, socioeconomic status, environmental sanitation \& personal hygiene arc important for elimination \& personal H. pylori infection.

- Multicentre and large scale epidemiological studies of $\mathrm{H}$. pylori infection and the association between its virulence factors and clinical outcome in different regions and populations.

- Public health education programs about H.pylori transmission, complications and resistance

- Early diagnosis and treatment of H. pylori infection minimize its complications.

- H. pylori monoclonal stool antigen test is recommended as a rapid, non-invasive, fast, cheap and easy for detection of active infection, monitoring therapy effectiveness and H.pylori eradication (6 weeks post treatment).

- H. pylori eradication should be confirmed to accelerate the healing and prevent relapse in PUD as well as GIT malignancies; as $\mathrm{H}$. pylori is classified as a class 1 carcinogen by IARC and WHO.

- Randomized-controlled trials are required to clarify' the H. pylori antimicrobial resistance to our market available regimens. 
- Moxifloxacin-based triple regimen is recommended $H$. pylori therapeutic regimen in our community with shorter course duration of treatment and better patient compliance.

\section{REFERENCES}

1. Malfertheiner P, Mégraud F, O'Morain CA et al. (2012): Management of Helicobacter pylori infection-the Maastricht IV/ Florence Consensus Report. Gut, 61(5): 646-64.

2. Chey WD, RM Zagari (2015): American College of Gastroenterology guideline on the management of Helicobacter pylori infection. Am J Gastroenterol., 102: 1808-25.

3. Proenca-Modena JL, Acrani GO, Brocchi M (2009): Helicobacter pylori: phenotypes, genotypes and virulence genes. Future Microbiol., 4(2): 223-40.

4. Chey W, Wong B (2007): American College of Gastroenterology guideline on the management of Helicobacter pylori infection. Am J Gastroenterol., 102: $1808-1825$.

5. Stenstrom B, Mcndis A, Marshall B (2008): Helicobacter pylori- the latest in diagnosis and treatment. Aust Fam Physician, 37(8): 608- 12.

6. Graham DY, Dore MP (2016): Helicobacter pylori therapy: a paradigm shift. Expert Rev Anti Infect Ther., 14(6): 577-85.

7. The American Society of Health-System Pharmacists (2017): Moxifloxacin Hydrochloride. https://toxnet.nlm.nih.gov/cgi-

bin/sis/search/a?dbs+hsdb: @term+@DOCNO+8026

8. Yamamoto Y, Hakld A, Friedman $\mathrm{H}$ et al. (1999): Nitazoxanide, a nitrothiazolide antiparasitic drug, is an anti-Helicobacter pylori agent with antivacuolating toxin activity. Chemother., 45: 303-12.

9. Siddiqui TR, Ahmed W, Arif A et al. (2016): Emerging trends of antimicrobial resistance in Helicobacter pylori isolates obtained from Pakistani patients: The need for consideration of amoxicillin and clarithromycin. J Pak Med Assoc., 66(6): 710-6.
10. Forde KA, Reddy KR (2009): Hepatitis C virus infection and immunomodulatory therapies. Clin Liver Dis., 13(3): 391-401.

11. Graham DY, Fischbach L (2010): Helicobacter pylori infection. N Engl J Med., 363(6): 595-6

12.Basu PP, Rayapudi K, Pacana T et al. (2011): A randomized study comparing levofloxacin, omcprazole, nitazoxanide, and doxycycline versus triple therapy for the eradication of Hclicobaoter pylori. Am J Gastroenterol., 106: $1970-5$

13. Gisbert JP, de la Morena F, Abraira $V$ et al. (2006): Accuracy of monoclonal stool antigen test for the diagnosis of H.pylori infection: a systematic review and metaanalysis. Am J Gastroenterol., 101: 1921-30.

14.Laine L, Yang H, Chang SC et al. (2012): Trends for incidence of hospitalization and death due to GI complications in the United States from 2001 to 2009. Am J Gastroenterol., 107: 1190-95.

15. Begovic G, Selmani R (2015): Etiological Factors in Urgent Gastroduodenal Ulcer. Pril (Makedon Akad Nauk Umet Odd Med Nauki), 36(2): 203-10.

16. Yakoob J, Abid S, Abbas $Z$ et al. (2010): Antibiotic susceptibility patterns of Helicobacter pylori and triple therapy in a high-prevalence area. Br J Biomed Sci., 67: 197-201.

17.Kobtan A, Abd Elsalam S, El Kalla F et al. (2016): A Nitazoxanide based treatment versus traditional therapy for Helicobacter pylori eradication: a single center experience. Medicine (Baltimore), 95: 3879-83.

18. Higuchi Y, Tkama M, Koichiro $N$ et al. (2006):Clinical investigations for H.Pylori infection. Clinical Drug Investig., 26(7): 403-14.

19.Hwang JJ, Lee DH, Yoon $H$ et al. (2015): Efficacy of moxifloxacin-based sequential and hybrid therapy for firstline Helicobacter pylori eradication. World J Gastroenterol., 21(35): 10234-41.

20. Mona S, Raghda T, Samah S et al. (2017): Randomized controlled study of a novel triple nitazoxanide (NTZ) containing therapeutic regimen. Helicobacter, 22: 1-5. 